Article

\title{
Fruit and Vegetable Knowledge and Intake within an Australian Population: The AusDiab Study
}

\author{
Caroline R. Hill ${ }^{1, *} \mathbb{0}$, Lauren C. Blekkenhorst ${ }^{1,2}$, Simone Radavelli-Bagatini ${ }^{1}$, Marc Sim ${ }^{1,2} \mathbb{D}$, \\ Richard J. Woodman ${ }^{3}(D)$, Amanda Devine ${ }^{1,2} \oplus$, Jonathan E. Shaw ${ }^{4,5}$, Jonathan M. Hodgson 1,2 ${ }^{\oplus}$, \\ Robin M. Daly ${ }^{6}$ and Joshua R. Lewis $1,2,7$ \\ 1 Institute for Nutrition Research, School of Medical and Health Sciences, Edith Cowan University, \\ Perth, WA 6000, Australia; 1.blekkenhorst@ecu.edu.au (L.C.B.); s.radavellibagatini@ecu.edu.au (S.R.-B.); \\ marc.sim@ecu.edu.au (M.S.); a.devine@ecu.edu.au (A.D.); jonathan.hodgson@ecu.edu.au (J.M.H.); \\ joshua.lewis@ecu.edu.au (J.R.L.) \\ 2 Medical School, The University of Western Australia, Nedlands, WA 6009, Australia \\ 3 Flinders Centre for Epidemiology and Biostatistics, Flinders University, Bedford Park, SA 5042, Australia; \\ richard.woodman@flinders.edu.au \\ 4 Clinical Diabetes and Epidemiology, Baker Heart and Diabetes Institute, Melbourne, VIC 3004, Australia; \\ jonathan.shaw@baker.edu.au \\ 5 School of Public Health and Preventive Medicine, Monash University, Clayton, VIC 3800, Australia \\ 6 Institute for Physical Activity and Nutrition, School of Exercise and Nutrition Science, Deakin University, \\ Burwood, VIC 3125, Australia; robin.daly@deakin.edu.au \\ 7 Centre for Kidney Research, Children's Hospital at Westmead School of Public Health, Sydney Medical \\ School, The University of Sydney, Sydney, NSW 2006, Australia \\ * Correspondence: caroline.hill@ecu.edu.au
}

Received: 19 October 2020; Accepted: 23 November 2020; Published: 25 November 2020

\begin{abstract}
Understanding the relationship between fruit and vegetable knowledge (FVK) and fruit and vegetable intake (FVI) is an important consideration for improved public health and successful targeting of health promotion messaging. The aim of this study was to investigate the association between FVK and FVI in Australian adults and to identify subgroups most at risk of poor knowledge. Using data from the Australian Diabetes, Obesity, and Lifestyle Study (AusDiab), we investigated associations between FVK and FVI, as well as demographic and lifestyle factors. Baseline FVK was measured using two self-reported questions. FVI was assessed using a validated, self-reported, food frequency questionnaire in 1999/00 (baseline), 2004/05, and 2011/12. Amongst the 8966 participants assessed at baseline, $24.1 \%$ had adequate, $73.0 \%$ had insufficient, and $2.9 \%$ had poor FVK. Using linear regression, those with insufficient or poor FVK reported significantly lower FVI (grams/day) compared to those with adequate FVK: baseline (coefficient $(95 \% \mathrm{CI}))$ : $-67.1(-80.0,-54.3)$ and $-124.0(-142.9$, $-105.1)$, respectively, whilst, at 12 years, the differences were $-42.5(-54.6,-30.5)$ and $-94.6(-133.8$, $-55.5)$ grams/day, respectively (all $p<0.001$ ). Poor FVK was more likely to be reported in males, older individuals ( $>65$ years), socio-economically disadvantaged, smokers, and those with insufficient physical activity/sedentary behavior. We demonstrate that having adequate knowledge of FVI, defined as knowing to consume fruit and vegetables several times a day for a well-balanced diet, is strongly associated with FVI, with several demographic and lifestyle factors predicting FVK. Health promotion messages aimed at increasing FVK should target these subgroups for maximal effect.
\end{abstract}

Keywords: health promotion; literacy; eating; diet; survey; questionnaire; fruit; vegetables 


\section{Introduction}

Lifestyle-related chronic diseases, such as diabetes and cardiovascular disease (CVD), continue to maintain their status as the leading cause of death worldwide [1]. Whilst 'optimal' fruit and vegetables intakes (FVI) is yet to be established, a large meta-analysis across 95 studies suggests that as many as 5.6 and 7.9 million deaths in 2013 were due to fruit and vegetables intakes (FVI) below 500 and $800 \mathrm{~g} /$ day, respectively [2]. Furthermore, in many countries, the vast majority of adults fail to even achieve the daily fruit and vegetable recommendations of $\geq 400 \mathrm{~g}$, as encouraged by the World Health Organization [3-6].

Specific phytochemicals within fruits and vegetables have shown multiple benefits for lowering chronic disease risk [7-9], such as organosulfur compounds in cruciferous and alliums, nitrate and vitamin $\mathrm{K}$ in green leafy vegetables, and saponins and phenolic compounds in legumes [10]. Carotenoids and phenolic compounds, such as flavonoids, found in many fresh fruits, also show health promoting benefits [8,9]. Higher fruit and vegetable intake overall is associated with reduced risk of cardiovascular disease [11-14], cancer [2], and all-cause mortality [2,13,15].

Considering these extensive benefits, understanding why habitual FVI remain poor is of major interest for public health professionals. There have been numerous barriers identified that influence FVI, including time, taste preferences, self-efficacy, inadequate cooking skills, social support, motivation, and willpower [16-20]. Those with lower diet quality and reduced FVI are also more likely to come from lower socio-economic backgrounds [21-23], more likely to consume higher discretionary foods [23], and more likely to have lower health literacy and nutrition knowledge [24-26].

Nutrition knowledge has been associated with improved dietary behaviors, including increased FVI [27-29]. Several theoretical frameworks seek to understand and improve dietary behaviors, with knowledge widely considered an integral part [30]. For example, the Theory of Planned Behavior (TPB) [31] and Social Cognitive Theory (SCT) [32] are common in public health in order to explain, predict, and change health behaviors. Nutrition-specific knowledge remains a core component of nutrition literacy, supporting the progress toward healthy choices [33]. Despite this, there remains multiple components of knowledge; knowing nutrition facts (i.e., declarative knowledge) does not necessarily always translate into improved dietary behaviors (i.e., procedural knowledge, such as how to prepare food) [30]. For example, Wallace et al. [34] describe using SCT among the elderly with dementia to raise nutrition literacy resulting in increased variety of vegetables and improved dietary behaviors. However, incorporating TPB into a randomized trial specifically to raise FVI among young adults found little correlation between intent and behavior (i.e., FVI) in the intervention group [35], indicating the complexity of the knowledge-behavior relationship.

Nevertheless, higher nutrition knowledge of fruit and vegetables and how often they should be consumed have been identified as factors influencing FVI [28]. Yet, high quality studies that explore subgroups, particularly those for whom FVI appears lowest, such as socio-economically disadvantaged, males, and lower educated people, are needed to direct further public health research. With this in mind, there are limited studies investigating the association between fruit and vegetable knowledge and actual intake, both within the global context and from an Australian perspective. Even less has been reported on the impact of fruit and vegetable knowledge on medium and long-term FVI, presenting a gap needing to be explored within this field.

Therefore, this study aimed to explore whether knowing to consume fruit and vegetables several times a day for a well-balanced diet is associated with a higher FVI among Australian adults aged $\geq 25$ years. We also sought to determine which subgroups within this cohort have lower fruit and vegetable knowledge, as well as which subgroups have lower FVI over 12 years of follow-up. By identifying those most at risk, additional and targeted public health messages can be implemented to increase FVI within these subgroups. Determining if such declarative knowledge (i.e., knowing how often to consume fruit and vegetables) impacts FVI will be an important contribution in the design of future public health messages. To our knowledge, we are the first to explore these associations over the medium to long-term across such a large cohort within the Australian population. 


\section{Materials and Methods}

\subsection{Data Collection}

This cross-sectional and prospective study was conducted using data from the Australian Diabetes, Obesity, and Lifestyle (AusDiab) study. As reported previously [36], AusDiab is a large population-based study involving a randomly selected sample of 11,247 Australian adults aged $\geq 25$ years. The sample was collected across 42 randomly selected census districts across the Northern Territory and Australia's six states. Each of these areas were selected using a selection probability proportional to the size of their population aged $\geq 25$ years. The original aim of the study was to explore the prevalence, risk factors, trends, knowledge, attitudes, and use of health services associated with diabetes mellitus and obesity within the Australian adult population. Interviews, anthropometrics, and blood measurements were collected on demographics, socio-economic status (SES), health and disease conditions, dietary intake, physical activity, and lifestyle habits, as well as attitudes and knowledge of a range of health-related areas. The original data collection occurred during May 1999 through to December 2000, with follow-ups in 2004/05 and 2011/12. The full study details and response rates are described elsewhere [36]. For this current study, only certain components of the original data collection were extracted for quantitative analysis.

Participant Selection

Participants were excluded if they were either pregnant or did not know they were pregnant $(n=89)$, or if they did not complete either the Food Frequency Questionnaire (FFQ) $(n=203)$ or the knowledge questionnaire $(n=1241)$. Those who reported consuming an implausible energy intake (defined as either $<3.3$ or $>17.5 \mathrm{MJ} /$ day in men and $<2.5$ or $>14.5 \mathrm{MJ} /$ day in women) were also excluded from analysis $(n=328)$. Those with missing data for covariates were excluded $(n=420)$. The final participant number for the cross-sectional analysis was 8966.

For the prospective component of this study, FVI from repeat FFQs was analyzed from 5204 participants after 5 years (collected during 2004/2005) and from 3549 participants at 12 years (collected during 2011/2012). Those participants not included had either dropped out or failed to complete the necessary FFQ (42\% in 2004/05 and 60\% in 2011/12, respectively). A participant flow diagram is illustrated in Figure 1.

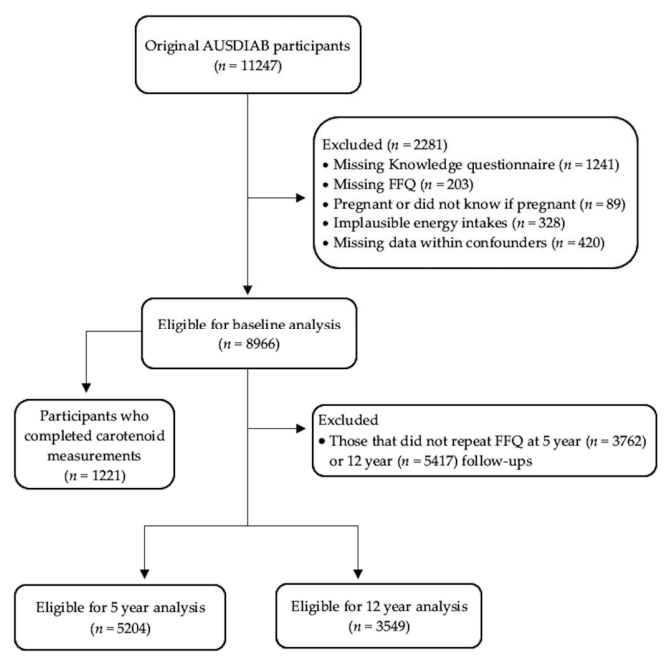

Figure 1. Participant flow diagram.

\subsection{Variables}

\subsubsection{Fruit and Vegetable Knowledge}

To determine fruit and vegetable knowledge of adequate intake, a score was calculated for each participant using raw data taken from the 'AusDiab Health Knowledge, Attitudes, and Practice 
Questionnaire' [37]. This questionnaire was administered at baseline by a trained interviewer. Knowledge of fruit and vegetable consumption was acquired using the following two questions; 'For a well-balanced diet, how often should adults eat FRUIT?' and 'For a well-balanced diet, how often should adults eat VEGETABLES?' (questions 7 and 9). A weighting of 25 was applied to those that responded 'several times a day', 20 applied to 'daily', 15 to 'every second day', 10 to 'twice a week', 5 to 'weekly or less often', and a weighting of 0 to those who answered 'don't know', for each question. This resulted in a five-point interval scale for fruit and vegetable knowledge. After assigning these weighting scores to participant responses, the authors of this study further created a self-derived 'fruit knowledge score' and a 'vegetable knowledge score', as well as a combined 'fruit and vegetable knowledge score', for each individual, with a maximum possible score of 25, 25, and 50, respectively. A score of $<20$ for either fruit or vegetables alone represented poor knowledge, and a score of 20 was insufficient, whilst 25 indicated adequate knowledge. Meanwhile, a score of $<40$ for fruit and vegetables combined represented poor knowledge, 40-45 indicated insufficient knowledge, and a maximum score of 50 indicated adequate fruit and vegetable knowledge levels. That is, a participant had to be adequate in both fruit knowledge and vegetable knowledge to be assigned the adequate score for total fruit and vegetable knowledge. As the knowledge questionnaire was administered once (i.e., at the commencement of the study), all fruit knowledge, vegetable knowledge and combined fruit and vegetable knowledge scores reflect a participant's knowledge only at baseline.

\subsubsection{Fruit and Vegetable Intake}

Dietary intake of fruit and vegetables was self-reported using the validated Anti-Cancer Council of Victoria Food Frequency Questionnaire, developed by the Cancer Council of Victoria [37-39]. Participants estimated how many pieces of fruit and how many different vegetables they typically ate each day. Responses were then verified using photographs to estimate serving sizes. We calculated total fruit intake, excluding fruit juice and tinned fruits due to their potential for high added sugar content, whilst total vegetable intake excluded hot chips as these are not recommended as part of a healthy eating pattern [40]. Table results display FVI as a continuous measurement in grams/day. The daily intake in serves was also calculated by dividing the total intake in grams by the recommended serving sizes as defined by the Australian Dietary Guidelines [40]. Therefore, one serving of fruit was $150 \mathrm{~g} /$ day, and one serving of vegetables was $75 \mathrm{~g} /$ day [40]. To calculate the proportion of participants meeting FVI recommendations, males were stratified into $\leq 50$ years, $51-70$ years, and $>70$ years, due to their differing serving size requirements [40].

\subsubsection{Serum Carotenoids}

Serum carotenoid levels $(\mathrm{mmol} / \mathrm{L})$ were measured at baseline in a subsample of participants $(n=1598)$, randomly selected from six areas in Queensland, Australia [41]. The carotenoids included were $\alpha$-carotene, $\beta$-carotene, $\beta$-cryptoxanthin, lutein/zeaxanthin, and lycopene, with each individually assayed using high performance liquid chromatography under procedure guidelines described [42]. A total carotenoid score was derived based on the sum for each of the aforementioned carotenoids, and, after our exclusion criteria was applied for this current study, a total of 1221 participants were included for analysis of carotenoid levels.

\subsection{Baseline Demographics and Assessments}

The following variables were collected at baseline and explored as confounders and predictors to intake: age (date of birth), sex (male/female), body mass index (BMI) $\left(\mathrm{kg} / \mathrm{m}^{2}\right)$, energy intake (MJ/day), relationship status (married, de facto, separated, divorced, widowed, or never married), physical activity level (sedentary as nil, insufficient $<150$ min per week, or sufficient $>150$ min per week), educational attainment (never to some high school or completed university or equivalent), smoking status (current, former-smoker, or never smoked), SEIFA (Socio-Economic Indexes for Areas) disadvantage score, self-reported history of CVD (yes/no), and the presence of Diabetes Mellitus 
(known Diabetes Mellitus, impaired fasting glucose, impaired glucose tolerance, new Diabetes Mellitus, or normal glucose levels). Full collection and measurement details have been described previously [36]. Briefly, anthropometrics for BMI were measured as described [43] and physical activity as per the Active Australia Survey Questionnaire [44]. For this particular study, we grouped participants based upon age (25-45 years, 45-65 years, >65 years) to represent young, middle-aged, and older-adult Australians. BMI groups were created based on universally accepted classifications [45]. Participants' SEIFA disadvantage scores were also grouped into quartiles according to cut-points predefined by 2001 Census data [46].

\subsection{Statistical Analysis}

Analyses were performed using STATA statistical software (version 15 StataCorp, College Station, TX, USA), with all cross-sectional analyses using the survey command to apply the necessary weighting for selection bias as a result of either under or over-sampling. The weighting applied was based upon 1998 Australian Census data for sex and age distribution. Prior to commencing analysis, the normality and distribution of variables were assessed to ensure all assumptions were met. Descriptive statistics are presented as weighted means and standard deviations, or weighted observations and percentages, where appropriate. These include baseline descriptives of participants, and their characteristics according to baseline knowledge scores, for both total fruit and vegetable knowledge, and fruit knowledge and vegetable knowledge, separately. All statistical outcomes are provided with a confidence limitation set at $95 \%$.

Linear regression was used to assess the relationship between baseline fruit and vegetable knowledge score categories (adequate, insufficient, and poor) and FVI at baseline, 5 years, and 12 years of follow-up, before and after adjustment for demographic and lifestyle factors. Adequate fruit and vegetable knowledge was used as the referent category. Model 1 was unadjusted, whilst model 2 included age, sex, education level, SEIFA disadvantage, energy intake, marital status, physical activity level, smoking status, BMI, presence of CVD, and diabetes status. Linear regression also assessed the association of baseline knowledge on intake, for both fruit and vegetables separately, as well as the association of the aforementioned demographic and lifestyle factors, upon intake. The positive correlation between FVI and total serum carotenoids, a marker of FVI, has been previously reported in a subgroup of this cohort [41]. We also explored the correlation between total carotenoids and fruit and vegetable knowledge categories in the subsample for whom carotenoids were measured. For this, we applied a square root log transformation on our continuous total carotenoid variable to normalize its distribution prior to applying survey command.

\subsection{Ethical Approval}

The AusDiab study was approved by the International Diabetes Institute Ethics Committee (Melbourne, Australia) and by The Human Research Ethics Committee of the Alfred Hospital (Melbourne, Australia).

\section{Results}

\subsection{Demographic Characteristics}

A total of 8966 individuals (49.8\% men) were included in our final cross-sectional analysis (Table 1$)$. The mean weighted age was 47.9 years $(S D=15.0)$ and ranged from $25-91$ years, whilst the mean weighted BMI was $26.6 \mathrm{~kg} / \mathrm{m}^{2}(S D=4.8)$. Those with adequate baseline fruit and vegetable knowledge scores were more likely to be female, younger, have completed university or equivalent, be a non-smoker, more socio-economically advantaged, physically active, married, and consume lower overall energy intake. Those with either CVD or diabetes were more likely to have the lowest (i.e., poor) baseline fruit and vegetable knowledge scores. There was no observed difference in a participant's knowledge score according to BMI status. 
Table 1. Baseline characteristics for all participants and by fruit and vegetable knowledge score category.

\begin{tabular}{|c|c|c|c|c|}
\hline & \multicolumn{4}{|c|}{ Baseline Knowledge of Fruit and Vegetable Intake } \\
\hline & Total Cohort & Adequate & Insufficient & Poor \\
\hline$n(\%)$ & 8966 & $2085(24.1)$ & $6596(73.0)$ & $285(2.9)$ \\
\hline Sex (men), $n(\%)$ & $4043(49.8)$ & $563(32.6)$ & $3291(54.8)$ & $189(67.5)$ \\
\hline \multicolumn{5}{|l|}{ Age groups, $n(\%)$} \\
\hline $25-45$ years & $3127(47.8)$ & $970(60.1)$ & $2060(43.7)$ & $97(47.6)$ \\
\hline $45-65$ years & 4188 (35.7) & $930(31.3)$ & 3144 (37.4) & $114(30.4)$ \\
\hline$>65$ years & $1651(16.5)$ & $185(8.6)$ & $1392(18.9)$ & $74(22.0)$ \\
\hline \multicolumn{5}{|l|}{ BMI groups, $n(\%)$} \\
\hline Underweight & $85(1.0)$ & $19(1.2)$ & $64(0.8)$ & $2(3.5)$ \\
\hline Normal & $3269(39.4)$ & $864(43.6)$ & $2324(38.3)$ & $81(34.0)$ \\
\hline Overweight & $3621(39.3)$ & $721(35.1)$ & $2758(40.6)$ & $142(41.5)$ \\
\hline Obese & $1991(20.3)$ & $481(20.2)$ & $1450(20.3)$ & $60(21.0)$ \\
\hline Energy intake (MJ/day), mean $\pm \mathrm{SD}$ & $8.8 \pm 3.1$ & $8.5 \pm 2.9$ & $8.8 \pm 3.1$ & $8.9 \pm 3.9$ \\
\hline \multicolumn{5}{|l|}{ Physical activity, $n(\%)$} \\
\hline Sedentary & $1523(15.8)$ & $269(11.8)$ & $1183(17.2)$ & $71(15.2)$ \\
\hline Insufficient & $2761(32.1)$ & $679(33.7)$ & $1997(31.3)$ & $85(38.6)$ \\
\hline Sufficient & $4682(52.1)$ & $1137(54.5)$ & $3416(51.5)$ & $129(46.2)$ \\
\hline \multicolumn{5}{|l|}{ Relationship status, $n(\%)$} \\
\hline Married & 6495 (72.6) & $1532(70.8)$ & $4772(73.5)$ & $191(65.6)$ \\
\hline De facto & $434(4.5)$ & $115(5.4)$ & $300(4.3)$ & $19(4.4)$ \\
\hline Separated & $228(2.4)$ & $61(3.9)$ & $157(1.8)$ & $10(4.7)$ \\
\hline Divorced & $534(5.1)$ & $119(5.0)$ & $396(5.2)$ & $19(4.7)$ \\
\hline Widowed & $559(5.3)$ & $82(3.4)$ & $453(5.8)$ & $24(8.5)$ \\
\hline Single & $716(10.0)$ & $176(11.5)$ & $518(9.4)$ & $22(12.1)$ \\
\hline \multicolumn{5}{|l|}{ Level of education, $n(\%)$} \\
\hline Never to some high school & $3586(35.9)$ & $668(29.8)$ & $2773(37.7)$ & $145(40.7)$ \\
\hline Completed university/equivalent & $5380(64.1)$ & $1417(70.2)$ & $3823(62.3)$ & $140(59.3)$ \\
\hline \multicolumn{5}{|l|}{ SEIFA Disadvantage, $n(\%)$} \\
\hline Quartile 1 (least disadvantaged) & $2634(35.1)$ & $695(38.1)$ & $1889(34.5)$ & $50(25.8)$ \\
\hline Quartile 2 & $3501(34.3)$ & $860(34.8)$ & $2539(34.3)$ & $102(32.0)$ \\
\hline Quartile 3 & $1437(16.1)$ & $283(16.0)$ & $1088(15.9)$ & $66(22.0)$ \\
\hline Quartile 4 (most disadvantaged) & $1394(14.5)$ & $247(11.1)$ & $1080(15.4)$ & $67(20.3)$ \\
\hline \multicolumn{5}{|l|}{ Smoking status, $n(\%)$} \\
\hline Current & $1366(15.7)$ & $207(9.7)$ & $1091(17.2)$ & $68(29.1)$ \\
\hline Former smoker & $2628(25.8)$ & $578(25.0)$ & $1951(26.0)$ & $99(29.9)$ \\
\hline Non-smoker & $4972(58.4)$ & $1300(65.3)$ & $3554(56.8)$ & $118(41.0)$ \\
\hline Self-reported CVD history, Yes, $n(\%)$ & $718(6.8)$ & $89(3.9)$ & $599(7.5)$ & $30(12.4)$ \\
\hline \multicolumn{5}{|l|}{ Diabetes status, $n(\%)$} \\
\hline Normal glucose levels & $6620(76.9)$ & $1686(83.8)$ & $4745(75.0)$ & $189(67.0)$ \\
\hline Known Diabetes Mellitus & $357(3.4)$ & $46(2.3)$ & $293(3.6)$ & $18(6.3)$ \\
\hline Impaired fasting glucose & $534(5.8)$ & $85(4.2)$ & $423(6.1)$ & $26(10.2)$ \\
\hline Impaired glucose tolerance & $1088(10.4)$ & $218(8.0)$ & $835(11.2)$ & 35 (11.9) \\
\hline New Diabetes Mellitus & $367(3.5)$ & $50(1.7)$ & $300(4.1)$ & $17(4.6)$ \\
\hline
\end{tabular}

All $n$ values are the number of observations, weighted using survey command. Baseline fruit and vegetable knowledge score: Poor defined as <40, Insufficient as 40-45, Adequate as 50; BMI body mass index; Underweight defined as $<18.5 \mathrm{~kg} / \mathrm{m}^{2}$, Normal as $18.5-24.9 \mathrm{~kg} / \mathrm{m}^{2}$, Overweight as $\geq 25 \mathrm{~kg} / \mathrm{m}^{2}$, and Obese as $\geq 30 \mathrm{~kg} / \mathrm{m}^{2} ; \mathrm{Physical}$ activity levels defined as Sedentary nil physical activity time, Insufficient as $<150 \mathrm{~min} /$ week and Sufficient as $>150$ min/week; SEIFA Disadvantage scores defined as Quartile 1 as >1068 (least disadvantaged), Quartile 2 as 1068-990, Quartile 3 as 989-928, and Quartile 4 as <928 (most disadvantaged); MJ, megajoules; CVD, cardiovascular disease.

When we explored baseline fruit and vegetable knowledge separately, those with adequate fruit knowledge were more likely to be female, consume lower overall energy intake, have completed university, be less socio-economically disadvantaged, not have diabetes, and not smoke (Supplementary Table S1). Fruit knowledge scores had no observed differences in reported physical activity level, marital status, BMI, or age group, nor in the presence of CVD. Those having adequate vegetable knowledge, however, were more likely to be female, younger, report sufficient physical activity levels, 
and be married. Adequate vegetable knowledge was also more likely to be observed in those who were more educated, less socio-economically disadvantaged, non-smokers, and to not have either CVD or diabetes. Neither BMI group nor overall energy intake appeared to have any observed differences in a participant's vegetable knowledge score.

\subsection{Fruit and Vegetable Knowledge and Intake}

Participants with adequate fruit and vegetable knowledge at baseline were found to also have greater FVI overall at baseline, in both our unadjusted and adjusted models (see Table 2).

Table 2. Relationship of fruit and vegetable intake (combined and discretely) with knowledge of fruit and vegetable intake at baseline, $n=8966^{\mathrm{a}}$.

\begin{tabular}{|c|c|c|c|}
\hline & \multicolumn{3}{|c|}{ Baseline Knowledge of Fruit and Vegetable Intake } \\
\hline & Adequate & Insufficient & Poor \\
\hline \multicolumn{4}{|l|}{ FVI (grams/day) } \\
\hline$n,(\%)$ & $2085(24.1)$ & $6596(73.0)$ & $285(2.9)$ \\
\hline Unadjusted & reference & $-57.5(-73.4,-41.7)$ & $-125.8(-144.7,-106.9)$ \\
\hline Multivariable adjusted ${ }^{b}$ & reference & $-67.1(-80.0,-54.3)$ & $-124.0(-142.9,-105.1)$ \\
\hline \multicolumn{4}{|l|}{ Fruit Intake (grams/day) } \\
\hline$n,(\%)$ & $3754(42.6)$ & $5031(55.6)$ & $181(1.8)$ \\
\hline Unadjusted & reference & $-65.8(-74.2,-57.3)$ & $-107.1(-130.0,-84.1)$ \\
\hline Multivariable adjusted ${ }^{\mathrm{b}}$ & reference & $-65.3(-73.3,-57.3)$ & $-96.7(-126.9,-66.4)$ \\
\hline \multicolumn{4}{|l|}{$\begin{array}{l}\text { Vegetable Intake } \\
\text { (grams/day) }\end{array}$} \\
\hline$n,(\%)$ & $2775(32.2)$ & $6032(65.9)$ & $159(1.9)$ \\
\hline Unadjusted & reference & $-11.2(-21.1,-1.3)$ & $-51.9(-68.1,-35.7)$ \\
\hline Multivariable adjusted ${ }^{b}$ & reference & $-16.1(-26.4,-5.8)$ & $-58.9(-77.6,-40.2)$ \\
\hline
\end{tabular}

CI: confidence interval. a Results are presented as coefficient (95\% CI) estimated using survey command for linear regression with the fruit and vegetable knowledge groups at baseline as the exposure of interest. The coefficient represents the difference (in grams/day) from the reference group. ${ }^{\mathrm{b}}$ Multivariable adjusted model included age, sex, BMI (body mass index), energy intake, relationship status, physical activity, level of education, SEIFA (Socio-economic index for areas) disadvantage, smoking status, diabetes status, and self-reported history of cardiovascular disease. Baseline fruit and vegetable knowledge score: Poor defined as <40, Insufficient 40-45, and Adequate as 50. Baseline fruit knowledge score: Poor defined as <20, Insufficient 20, and Adequate as 25. Baseline vegetable knowledge score: Poor defined as $<20$, Insufficient 20, and Adequate as 25.

In our adjusted model, we found that increasing age (both $45-65$ year and $>65$ year age groups), being female, consuming greater energy intake, engaging in >150 min of physical activity per week, being a known diabetic, and either a former or non-smoker was significantly and positively associated with higher FVI (see Table 3). 
Table 3. Relationship of the demographic and lifestyle factors in our adjusted model investigating the association of baseline fruit and vegetable knowledge scores with baseline fruit and vegetable intake.

\begin{tabular}{|c|c|c|c|}
\hline \multicolumn{4}{|c|}{ Baseline Fruit and Vegetable Intake (grams/day) } \\
\hline Model $2^{b}$ & & Coefficient & $(95 \% \mathrm{CI})$ \\
\hline \multirow[t]{3}{*}{ Baseline Knowledge Score } & Adequate & reference & \\
\hline & Insufficient & -67.1 & $(-80.0,-54.3)$ \\
\hline & Poor & -124.0 & $(142.9,105.1)$ \\
\hline \multirow[t]{2}{*}{ Sex } & Male & reference & \\
\hline & Female & 25.7 & $(19.4,32.0)$ \\
\hline \multirow[t]{3}{*}{ Age Groups } & $25-45$ years & reference & \\
\hline & $45-65$ years & 59.3 & $(44.9,73.6)$ \\
\hline & $>65$ years & 84.9 & $(64.4,105.3)$ \\
\hline \multirow[t]{4}{*}{ BMI Groups } & Normal & reference & \\
\hline & Underweight & -36.6 & $(-92.2,18.9)$ \\
\hline & Overweight & 1.6 & $(-10.5,13.7)$ \\
\hline & Obese & 8.7 & $(-14.0,31.4)$ \\
\hline Energy Intake & (megajoules/day) & 17.8 & $(16.0,19.5)$ \\
\hline \multirow[t]{3}{*}{ Physical Activity Level } & Sedentary & reference & \\
\hline & Insufficient & 2.5 & $(-17.6,22.5)$ \\
\hline & Sufficient & 33.4 & $(19.4,47.4)$ \\
\hline \multirow[t]{6}{*}{ Marital Status } & Married & reference & \\
\hline & De facto & -14.5 & $(-34.7,5.7)$ \\
\hline & Separated & -16.6 & $(-53.8,20.5)$ \\
\hline & Divorced & -16.1 & $(-42.2,9.9)$ \\
\hline & Widowed & -11.1 & $(-45.4,23.2)$ \\
\hline & Single & -2.3 & $(-20.8,16.2)$ \\
\hline \multirow[t]{2}{*}{ Education Level } & $\begin{array}{c}\text { Never to some high } \\
\text { school }\end{array}$ & reference & \\
\hline & University or equivalent & -7.9 & $(-17.4,1.6)$ \\
\hline \multirow[t]{4}{*}{ SEIFA Disadvantage } & Quartile 1 (least) & reference & \\
\hline & Quartile 2 & 0.1 & $(-16.3,16.4)$ \\
\hline & Quartile 3 & 8.3 & $(-15.4,31.9)$ \\
\hline & Quartile 4 (most) & 10.9 & $(-19.2,41.0)$ \\
\hline \multirow[t]{3}{*}{ Smoking Status } & Current smoker & reference & \\
\hline & Former smoker & 59.1 & $(38.7,79.5)$ \\
\hline & Non-smoker & 65.3 & $(45.1,85.5)$ \\
\hline \multirow[t]{2}{*}{ Self-reported history of CVD } & Yes & reference & \\
\hline & No & -18.2 & $(-39.1,2.7)$ \\
\hline \multirow[t]{5}{*}{ Diabetes Status } & Normal glucose levels & reference & \\
\hline & Known Diabetes Mellitus & 35.6 & $(6.4,64.7)$ \\
\hline & New Diabetes Mellitus & -5.3 & $(-44.0,33.5)$ \\
\hline & Impaired fasting glucose & 1.2 & $(-22.5,24.9)$ \\
\hline & $\begin{array}{l}\text { Impaired glucose } \\
\text { tolerance }\end{array}$ & -10.5 & $(-33.8,12.8)$ \\
\hline
\end{tabular}

CI: confidence interval. ${ }^{\mathrm{b}}$ Results are presented as coefficient (95\% CI) estimated using survey command for linear regression, adjusted for age group, sex, BMI, energy intake, relationship status, physical activity, level of education, SEIFA (Socio-economic index for areas) disadvantage, smoking status, diabetes status, and self-reported history of cardiovascular disease. Baseline fruit and vegetable knowledge score: Poor defined as $<40$, Insufficient $40-45$, and Adequate as 50 . Physical activity levels defined as Sedentary nil physical activity time, Insufficient as $<150 \mathrm{~min} /$ week, and Sufficient as $>150 \mathrm{~min} /$ week; SEIFA disadvantage scores defined as Quartile 1 as $>1068$ (least disadvantaged), Quartile 2 as 1068-990, Quartile 3 as 989-928, and Quartile 4 as $<928$ (most disadvantaged); BMI, body mass index; Underweight defined as $<18.5 \mathrm{~kg} / \mathrm{m}^{2}$, Normal as $18.5-24.9 \mathrm{~kg} / \mathrm{m}^{2}$, Overweight as $\geq 25 \mathrm{~kg} / \mathrm{m}^{2}$, and Obese as $\geq 30$ $\mathrm{kg} / \mathrm{m}^{2} ; \mathrm{CVD}$, cardiovascular disease. 
Variables associated with FVI separately were also explored at baseline (Supplementary Table S2). Whilst differences occurred when observing FVI separately, of significance was that having completed university or equivalent was significantly associated with less vegetable intake $(\beta=-11.9, p=<0.001)$, as was being widowed $(\beta=-13.6, p=0.008)$ over those who were married. Those not reporting CVD consumed less vegetable intake $(\beta=-12.9, p<0.001)$. Those in a de facto relationship consumed significantly lower fruit $(\beta=-19.9, p=0.026)$ over their married counterparts, and those most socio-economically disadvantaged consumed higher fruit $(\beta=9.6, p=0.048)$.

\subsection{Fruit and Vegetable Knowledge and Intake over 12 years}

Linear regression analysis found that insufficient and poor knowledge at baseline was significantly associated with lower FVI at both 5 and 12 years, in both our unadjusted and adjusted models (Table 4).

Table 4. Relationship of total fruit and vegetable intakes at both 5 years $(n=5204)$ and 12 years $(n=3549)$, with knowledge of fruit and vegetable intake reported at baseline ${ }^{\mathrm{a}}$.

\begin{tabular}{|c|c|c|c|}
\hline & \multicolumn{3}{|c|}{ Baseline Knowledge of Fruit and Vegetable Intake } \\
\hline & Adequate & Insufficient & Poor \\
\hline \multicolumn{4}{|l|}{ FVI (grams/day): 5 years } \\
\hline$n,(\%)$ & $1298(24.9)$ & $3775(72.5)$ & $131(2.5)$ \\
\hline Unadjusted & reference & $-45.2(-56.1,-34.3)$ & $-128.2(-159.3,-97.1)$ \\
\hline Multivariable adjusted ${ }^{b}$ & reference & $-50.4(-61.4,-39.4)$ & $-122.2(-152.7,-91.6)$ \\
\hline \multicolumn{4}{|l|}{$\begin{array}{c}\text { FVI (grams/day): } 12 \\
\text { years }\end{array}$} \\
\hline$n,(\%)$ & $1022(28.8)$ & $2457(69.2)$ & $70(2.0)$ \\
\hline Unadjusted & reference & $-37.5(-49.5,-25.6)$ & $-92.0(-131.7,-52.4)$ \\
\hline Multivariable adjusted ${ }^{b}$ & reference & $-42.5(-54.6,-30.5)$ & $-94.6(-133.8,-55.5)$ \\
\hline $\begin{array}{l}\text { CI: confidence interval. }{ }^{a} \mathrm{P} \\
\text { regression with the fruit a } \\
\text { represents the difference (ir } \\
\text { BMI (body mass index), ene } \\
\text { index for areas) disadvant } \\
\text { Baseline fruit and vegetabl }\end{array}$ & $\begin{array}{l}\text { re presented a } \\
\text { table knowled } \\
\text { day) from the } \\
\text { ke, relationship } \\
\text { king status, di } \\
\text { ledge score: } \mathrm{Pc}\end{array}$ & $\begin{array}{l}\text { nt }(95 \% \mathrm{CI}) \text { estimated us } \\
\text { s at baseline as the expo } \\
\text { group. }{ }^{b} \text { Multivariable ac } \\
\text { nysical activity, level of ed } \\
\text { tus, and self-reported hi } \\
\text { d as }<40 \text {, Insufficient } 40\end{array}$ & $\begin{array}{l}\text { rvey command for linear } \\
\text { f interest. The coefficient } \\
\text { model included age, sex, } \\
\text { n, SEIFA (Socio-economic } \\
\text { of cardiovascular disease. } \\
\text { d Adequate as } 50 \text {. }\end{array}$ \\
\hline
\end{tabular}

\subsection{Fruit and Vegetable Knowledge and Serum Carotenoids}

We found a weakly positive, although significant, association between total serum carotenoids and baseline fruit and vegetable knowledge $(\mathrm{r}=0.14, p=0.006)$. This correlation with carotenoids was similar for both fruit knowledge $(r=0.14, p=0.021)$ and vegetable knowledge $(r=0.12, p=0.011)$ separately.

\section{Discussion}

In our study, we observed that only a quarter of subjects knew to consume fruit and vegetables several times a day, for a well-balanced diet. Adequate knowledge was positively associated with self-reported FVI and total serum carotenoids, a biomarker of FVI. The positive association of adequate knowledge on overall intake was evident and remained even after controlling for many demographic and lifestyle factors. Our results support the continuation of public health messages to promote fruit and vegetable knowledge in order to raise habitual intakes across the Australian population. Specifically, we found particular attention may be warranted for males, older Australians ( $>65$ years), those most socio-economically disadvantaged, current smokers and those not engaging in sufficient physical activity as these attributes were each associated with lower knowledge scores. Furthermore, novel methods to engage the entire population to improve knowledge and increase FVI should be a high priority, particularly for vegetables, with reported intakes across our entire cohort highly inadequate. This clearly illustrates that, whilst we observed a higher FVI in those reporting higher FVK, this by no means implies that those with 'adequate' FVK, as assessed by the AusDiab questionnaire, 
cannot still potentially improve other aspects of their FVK. Unique to this study was our ability to assess weighted mean FVI at three separate timepoints over 12 years, as well as to demonstrate that the association with baseline knowledge remained, but also weakened, over time.

\subsection{The Association between Fruit and Vegetable Knowledge and Intake}

Having higher knowledge, for both fruit and vegetables separately, or fruit and vegetables combined, was associated with higher FVI. For those with adequate knowledge, there was an associated higher (mean $124.0 \mathrm{~g}$ /day) FVI in comparison to those with poor knowledge. At 5 and 12 years, this association was slightly attenuated (mean difference $122.2 \mathrm{~g} /$ day and 94.6 g/day, respectively) although the positive association remained in both unadjusted and adjusted models. Whilst other observational studies have also identified a positive association between knowledge and intake $[17,27,47-52]$, this study appears to be the first to provide evidence of this relationship over the long term. Previous intervention studies (typically involving a pre-post knowledge or an education component), for the most part, have found similar positive results with knowledge increasing FVI by $\sim 0.1-1.8$ cups per day, within a three-month duration [53-58]. Meanwhile, a systematic review and meta-analysis by Lara et al. [59] found that dietary education increased FVI by $86 \mathrm{~g}$ per day after 4 to 12 months, which was maintained ( $87 \mathrm{~g}$ per day) after 13-58 months. Nonetheless, not all education programs have successfully resulted in increases in FVI over time [60,61]. A study in Western Australia $(n=2854)$ found that, despite increased awareness of the "Go for $2 \& 5$ " fruit and vegetable campaign, FVI actually decreased over a nine-year period [62]. Participants perceived that their intake of fruits and vegetables was already adequate (34.5\% and 59.3\%, respectively), reporting that insufficient time and preparatory efforts required as the main difficulties to increasing consumption. These findings support the existence of additional barriers toward FVI, particularly for vegetables, that remain unanswered $[17,20]$.

Previously identified barriers to FVI include neophobias, habits, taste preferences, religion, time-constraints, convenience, perceived cost, insufficient self-efficacy, and social support [16,20,63]. Moreover, the overall reduced consumption of vegetables, along with the lower influence of knowledge upon intake, when compared to fruit, suggests greater barriers to vegetable intake. This has been reported by others $[16,61,64]$ inferring that public health messages targeting vegetables separately are warranted. Multiple barriers have been identified to increasing vegetable intake, including one's lack of cooking and preparatory skills, plus the additional time requirements for cooking [65]. Furthermore, studies have also found that often people are unaware their consumption is low, particularly for vegetables [16]. Despite widespread awareness of Western Australia's 5\&2 campaign, participants assumed this vegetable recommendation was 'aspirational', unachievable, and unnecessary for any greater health benefit $[62,63,66]$. Often, knowledge is the first step in behavior change [30], and, as such, greater efforts to target fruit and vegetable messages across the entire population are needed and confirmed by these findings.

\subsection{Targeting Those at Risk}

In line with previous studies, we found that fruit and vegetable knowledge was highest among females [27,48,67-69], the younger-to-middle aged [28,48,70], those more educated [51,52,68-70], married [27,68], less socio-economically disadvantaged [68,70,71], those who engaged in more physical activity [51], and in non-smokers [51,71]. Regardless, this cohort reported an average intake of just 1.3 servings (198 g/day) of fruit and 2.2 servings (168 g/day) of vegetables per day, consistent with previous findings of widespread inadequacy $[3,16,22,27,52,58,71]$. According to recommendations set out by the Australian Dietary Guidelines [40], these average intakes translated to only 22\% of participants achieving recommendations for fruit (2 servings or $300 \mathrm{~g}$ ), 1.5\% achieving recommendations for vegetables (5-6 servings or 375-450 g), and only $0.7 \%$ achieving recommendations for both combined. This confirms the need for wide-reaching and novel methods to influence FVI across the entire Australian population. Nevertheless, targeting of messages is particularly warranted for smokers and 
sedentary individuals, each of which consistently reported both lower FVI and lower knowledge in all models, more so when considering the well-established harmful effects of smoking and sedentary behavior on CVD risk [72,73]. Although previous research in a subsample of this cohort [21] found that higher socio-economic status (SES) was positively associated with higher diet quality (measured by the Dietary Guidelines Index), we found little difference in FVI by either education or SEIFA disadvantage. In fact, those who were the most socio-economic disadvantaged actually reported higher fruit intake $(9.6 \mathrm{~g} /$ day) when compared to those who were the least, although this was not evident for vegetables separately, nor for overall FVI combined. It appears that some studies show a positive association between SES and FVI [16,21,22], whilst others appear mixed [74,75], indicating further investigations are warranted. Briefly, we found those with CVD and/or diabetes had lower knowledge, and long-term FVI in these subgroups were less than adequate. Considering the positive impact of FVI on cardiometabolic disorders [7-9], targeting this subgroup is likely to attenuate disease progression and overall risk.

\section{Strengths and Limitations}

This study had several strengths. The data was part of Australia's largest population-based diabetes study, representing both male and female adults across the lifespan. An extensive number of demographic and lifestyle variable were available to explore as potential confounders within our adjusted model, and FVI was assessed using a validated FFQ at three separate timepoints over 12 years. Furthermore, self-reported FVI has previously been validated against objectively measured serum carotenoids, a biomarker of FVI, in a subsample of this cohort [41]. The additional, albeit weak correlation between serum carotenoids and knowledge support results between FVK and FVI.

Some limitations were also present. Firstly, the cross-sectional nature of this study cannot assess causality. Secondly, we understand our knowledge questions reported only declarative (i.e., facts), not procedural (i.e., how to), knowledge. Thirdly, we recognize our knowledge questionnaire as a major limitation to the study, being a blunt tool that had not been formerly validated for the assessment of FVK, and, as such, this may have introduced the potential for bias. The field of nutrition knowledge only began to emerge in the early 2000s; therefore, at the time of data collection (1999/2000), validated knowledge instruments were not available [30]. The AusDiab FVK component of the questionnaire was limited to two simple questions, which were likely to capture only a component of an individual's overall FVK and/or not fully assess a participants FVK; therefore, this may have influenced our results. The lack of homogeneity through the use of non-validated instruments to assess dietary knowledge appears to be a common limitation in similar studies $[26,30]$. Future research in this area is urgently needed to address this issue and always ensure well validated measures of FVK are available to accurately capture both declarative and procedural knowledge across the general population. However, objective biomarkers (i.e., serum carotenoids) have previously positively correlated with FVI [41], and then weakly, but significantly, with FVK in the current investigation, indicating a positive association between FVK and FVI. Furthermore, the interpretation and weighting applied to responses from the knowledge questionnaire to create our knowledge scores are recognized as a potential limitation. The nature of the questions asked, and the choice of responses offered [37], may have created an automated response of 'daily', thereby resulting in an inflation of participants in our 'insufficient' knowledge group. Whilst it could also be suggested that there was little difference in participants responding 'daily' to 'several times a day', it is very unlikely one can successfully reach the recommended FVI in a single setting of 'daily', therefore adding weight to our decision to assign 'several times a day' as adequate. In addition, knowledge was also only measured at baseline, and we cannot rule out additional knowledge gains over time through other means. Nor, can we rule out the impacts of other major public health campaigns upon knowledge within the Australian landscape over this timeframe. Furthermore, we reported a 42 to $60 \%$ drop-out from baseline to the 5 - and 12-year timepoints, which may have introduced selection bias. Lastly, the original cohort was randomly selected to optimize inferences toward the wider Australian population, albeit with low representation 
of indigenous or rural populations. Although cross-sectional weighting was applied to minimize for age and gender selection bias, participants were over-represented by higher education and higher socio-economic subgroups [36]. This may have impacted the generalizability of our results to lower socio-economic subgroups and possibly our ability to observe differences in FVI across SEIFA groups.

\section{Conclusions}

Our study demonstrated that FVI was highly inadequate among this Australian adult cohort and that intake could be increased by improving fruit and vegetable knowledge. Public health messages should have greater focus on improving knowledge of fruit and vegetable recommendations to encourage higher FVI across all meals, particularly for vegetables. Furthermore, these messages likely require repeated exposures over time to reach and maintain their potential benefits for public health. In addition, providing targeted messages that highlight the need to increase FVI in subgroups for whom intake is particularly low, such as males, smokers, and for those that are sedentary or have low physical activity levels, is warranted. There are many complexities to changing dietary behavior; however, we have found that essentially stripping back to one important aspect of knowledge, i.e., knowing how often to consume fruit and vegetables for a well-balanced diet, is an important component of nutrition literacy and potentially increasing FVI. Yet, according to our study, only one-quarter of Australian adults acquire this knowledge. Whilst various theoretical frameworks can be used to influence dietary behavior, establishing FVK is an integral step in health promotion. To our knowledge, we are the first to show that raising awareness of the need to consume fruit and vegetables several times a day for a well-balanced diet could potentially improve medium to long-term FVI.

Supplementary Materials: The following are available online at http://www.mdpi.com/2072-6643/12/12/3628/s1, Table S1: Baseline characteristics by category of fruit knowledge and vegetable knowledge, Table S2: Relationship of the demographic and lifestyle factors in our adjusted model investigating the association of baseline fruit knowledge and baseline vegetable knowledge scores with respective baseline fruit and vegetable intakes (grams/day).

Author Contributions: Conceptualization, C.R.H., L.C.B., and J.R.L.; Formal analysis, C.R.H. and L.C.B.; Methodology, C.R.H., L.C.B., S.R.-B., M.S., and J.R.L.; Project administration, C.R.H., L.C.B., and J.R.L.; Supervision, L.C.B. and J.R.L.; Writing-Original draft, C.R.H.; Writing-Review and editing, C.R.H., L.C.B., S.R.-B., M.S., R.J.W., A.D., J.E.S., J.M.H., R.M.D., and J.R.L. All authors have read and agreed to the published version of the manuscript.

Funding: This research received no additional nor specific funding. Original funding as per the acknowledgements below. The salary of LCB is supported by a National Health and Medical Research Council (NHMRC) of Australia Emerging Leadership Investigator Grant (ID: 1172987) and a National Heart Foundation of Australia Post-Doctoral Research Fellowship (ID: 102498). The salary of A/Prof Lewis is supported by a National Heart Foundation Future Leader Fellowship (ID: 102817).

Acknowledgments: The authors would like to thank the Baker Heart and Diabetes Institute (formerly the International Diabetes Institute) for their co-ordination and management of the study, and for providing data access, support and assistance for our analysis. The AusDiab study, initiated and coordinated by the International Diabetes Institute, and subsequently coordinated by the Baker Heart and Diabetes Institute, gratefully acknowledges the support and assistance given by: A. Allman, K. Anstey, B. Atkins, B. Balkau, E. Barr, S. Bennett, A. Cameron, S. Chadban, S. Colagiuri, M. de Courten, M. Dalton, M. D'Embden, D. Dunstan, T. Dwyer, D. Jolley, A. Kavanagh, I. Kemp, P. Magnus, J. Matthews, D. McCarty, A. Meehan, S. Murray, K. O’Dea, N. Owen, P. Phillips, K. Polkinghorne, P. Popplewell, C. Reid, A. Stewart, R. Tapp, H. Taylor, T. Wellborn, F. Wilson, and P. Zimmet, and all the study participants. In addition, for funding or logistical support, we are grateful to: National Health and Medical Research Council (NHMRC grants 233200 and 1007544 ), Australian Government Department of Health and Ageing, Abbott Australasia Pty Ltd., Alphapharm Pty Ltd., Amgen Australia, AstraZeneca, Bristol-Myers Squibb, City Health Centre-Diabetes Service-Canberra, Department of Health and Community Services-Northern Territory, Department of Health and Human Services-Tasmania, Department of Health-New South Wales, Department of Health-Western Australia, Department of Health-South Australia, Department of Human Services-Victoria, Diabetes Australia, Diabetes Australia Northern Territory, Eli Lilly Australia, Estate of the Late Edward Wilson, GlaxoSmithKline, Jack Brockhoff Foundation, Janssen-Cilag, Kidney Health Australia, Marian \& FH Flack Trust, Menzies Research Institute, Merck Sharp \& Dohme, Novartis Pharmaceuticals, Novo Nordisk Pharmaceuticals, Pfizer Pty Ltd., Pratt Foundation, Queensland Health, Roche Diagnostics Australia, Royal Prince Alfred Hospital, Sydney, Sanofi Aventis, sanofi-synthelabo, and the Victorian Government's Operational Infrastructure Support Program. 
Conflicts of Interest: The authors declare no conflict of interest. The funders had no role in the design of the study; in the collection, analyses, nor interpretation of data; in the writing of the manuscript, or in the decision to publish the results.

Data Availability: Our researchers were granted access to data for this study from the AusDiab steering committee under a licensing agreement. Requests for its use and access for research are made possible through contact with the steering committee of AusDiab.

\section{References}

1. World Health Organisation. Global Health Estimates 2016: Disease Burden by Cause, Age, Sex, by Country and by Region, 2000-2016; World Health Institution: Geneva, Switzerland, 2018.

2. Aune, D.; Giovannucci, E.; Boffetta, P.; Fadnes, L.T.; Keum, N.; Norat, T.; Greenwood, D.C.; Riboli, E.; Vatten, L.J.; Tonstad, S. Fruit and vegetable intake and the risk of cardiovascular disease, total cancer and all-cause mortality-a systematic review and dose-response meta-analysis of prospective studies. Int. J. Epidem. 2017, 46, 1029-1056. [CrossRef]

3. Australian Bureau of Statistics. National Health Survey: First Results, 2017-18; Commonwealth of Australia: Sydney, Australia, 2018.

4. Hall, J.N.; Moore, S.; Harper, S.B.; Lynch, J.W. Global Variability in Fruit and Vegetable Consumption. Am. J. Prev. Med. 2009, 36, 402-409.e5. [CrossRef]

5. Wallace, T.C.; Bailey, R.L.; Blumberg, J.B.; Burton-Freeman, B.; Chen, C.-Y.O.; Crowe-White, K.M.; Drewnowski, A.; Hooshmand, S.; Johnson, E.; Lewis, R.; et al. Fruits, vegetables, and health: A comprehensive narrative, umbrella review of the science and recommendations for enhanced public policy to improve intake. Crit. Rev. Food Sci. Nutr. 2020, 60, 2174-2211. [CrossRef]

6. World Health Organisation and Food and Agriculture Organization of the United Nations. Fruit and Vegetables for Health: Report of a Joint FAO/WHO Workshop on Fruit and Vegetables for Health, 1-3 September 2004, Kobe, Japan; World Health Organisation: Geneva, Switzerland, 2004.

7. Habauzit, V.; Morand, C. Evidence for a protective effect of polyphenols-containing foods on cardiovascular health: An update for clinicians. Ther. Adv. Chronic Dis. 2011, 3, 87-106. [CrossRef]

8. Liu, R.H. Health-Promoting Components of Fruits and Vegetables in the Diet. Adv. Nutr. 2013, 4, 384S-392S. [CrossRef]

9. Zhu, F.; Du, B.; Xu, B. Anti-inflammatory effects of phytochemicals from fruits, vegetables, and food legumes: A review. Crit. Rev. Food Sci. Nutr. 2018, 58, 1260-1270. [CrossRef] [PubMed]

10. Blekkenhorst, L.C.; Sim, M.; Bondonno, C.P.; Bondonno, N.P.; Ward, N.C.; Prince, R.L.; Devine, A.; Lewis, J.R.; Hodgson, J.M. Cardiovascular Health Benefits of Specific Vegetable Types: A Narrative Review. Nutrients 2018, 10, 595. [CrossRef] [PubMed]

11. Gan, Y.; Tong, X.; Li, L.; Cao, S.; Yin, X.; Gao, C.; Herath, C.; Li, W.; Jin, Z.; Chen, Y.; et al. Consumption of fruit and vegetable and risk of coronary heart disease: A meta-analysis of prospective cohort studies. Int. J. Cardiol. 2015, 183, 129-137. [CrossRef] [PubMed]

12. Hu, D.; Huang, J.; Wang, Y.; Zhang, D.; Qu, Y. Fruits and Vegetables Consumption and Risk of Stroke. Stroke 2014, 45, 1613-1619. [CrossRef] [PubMed]

13. Wang, X.; Ouyang, Y.; Liu, J.; Zhu, M.; Zhao, G.; Bao, W.; Hu, F.B. Fruit and vegetable consumption and mortality from all causes, cardiovascular disease, and cancer: Systematic review and dose-response meta-analysis of prospective cohort studies. BMJ 2014, 349, g4490. [CrossRef]

14. Wu, L.; Sun, D.; He, Y. Fruit and vegetables consumption and incident hypertension: Dose-response meta-analysis of prospective cohort studies. J. Hum. Hypertens. 2016, 30, 573-580. [CrossRef] [PubMed]

15. Nguyen, B.; Bauman, A.E.; Gale, J.; Banks, E.; Kritharides, L.; Ding, D. Fruit and vegetable consumption and all-cause mortality: Evidence from a large Australian cohort study. Int. J. Behav. Nutr. Phys. Act. 2016, 13, 9. [CrossRef] [PubMed]

16. Chapman, K.; Havill, M.; Watson, W.L.; Wellard, L.; Hughes, C.; Bauman, A.; Allman-Farinelli, M. Time to address continued poor vegetable intake in Australia for prevention of chronic disease. Appetite 2016, 107, 295-302. [CrossRef] [PubMed] 
17. Erinosho, T.O.; Parks, C.A.; Nebeling, L.C.; Moser, R.P.; Shaikh, A.R.; Resnicow, K.; Oh, A.Y.; Yaroch, A.L. Development and Implementation of the National Cancer Institute's Food Attitudes and Behaviors Survey to Assess Correlates of Fruit and Vegetable Intake in Adults. PLoS ONE 2015, 10, e0115017. [CrossRef] [PubMed]

18. Mc Morrow, L.; Ludbrook, A.; MacDiarmid, J.; Olajide, D. Perceived barriers towards healthy eating and their association with fruit and vegetable consumption. J. Public Health 2016, 39, fdw038-338. [CrossRef] [PubMed]

19. Pinho, M.G.M.; MacKenbach, J.D.; Charreire, H.; Oppert, J.-M.; Bárdos, H.; Glonti, K.; Rutter, H.; Compernolle, S.; De Bourdeaudhuij, I.; Beulens, J.W.J.; et al. Exploring the relationship between perceived barriers to healthy eating and dietary behaviours in European adults. Eur. J. Nutr. 2018, 57, 1761-1770. [CrossRef] [PubMed]

20. Shaikh, A.R.; Yaroch, A.L.; Nebeling, L.; Yeh, M.-C.; Resnicow, K. Psychosocial Predictors of Fruit and Vegetable Consumption in Adults. Am. J. Prev. Med. 2008, 34, 535-543.e11. [CrossRef]

21. Backholer, K.; Spencer, E.; Gearon, E.; Magliano, D.J.; McNaughton, S.A.; E Shaw, J.; Peeters, A. The association between socio-economic position and diet quality in Australian adults. Public Health Nutr. 2015, 19, 477-485. [CrossRef]

22. Olstad, D.L.; Leech, R.M.; Livingstone, K.M.; Ball, K.; Thomas, B.; Potter, J.; Cleanthous, X.; Reynolds, R.; McNaughton, S.A. Are dietary inequalities among Australian adults changing? A nationally representative analysis of dietary change according to socioeconomic position between 1995 and 2011-13. Int. J. Behav. Nutr. Phys. Act. 2018, 15, 1-19. [CrossRef]

23. Sui, Z.; Wong, W.K.; Louie, J.C.Y.; Rangan, A. Discretionary food and beverage consumption and its association with demographic characteristics, weight status, and fruit and vegetable intakes in Australian adults. Public Health Nutr. 2017, 20, 274-281. [CrossRef]

24. Aaby, A.; Friis, K.; Christensen, B.; Rowlands, G.; Maindal, H.T. Health literacy is associated with health behaviour and self-reported health: A large population-based study in individuals with cardiovascular disease. Eur. J. Prev. Cardiol. 2017, 24, 1880-1888. [CrossRef] [PubMed]

25. Lim, S.; Beauchamp, A.; Dodson, S.; O’Hara, J.; McPhee, C.; Fulton, A.; Wildey, C.; Osborne, R. Health literacy and fruit and vegetable intake in rural Australia. Public Health Nutr. 2017, 20, 2680-2684. [CrossRef] [PubMed]

26. Spronk, I.; Kullen, C.; Burdon, C.; O'Connor, H. Relationship between nutrition knowledge and dietary intake. Br. J. Nutr. 2014, 111, 1713-1726. [CrossRef] [PubMed]

27. Appleton, K.M.; Krumplevska, K.; Smith, E.; Rooney, C.; McKinley, M.C.; Woodside, J.V. Low fruit and vegetable consumption is associated with low knowledge of the details of the 5-a-day fruit and vegetable message in the UK: Findings from two cross-sectional questionnaire studies. J. Hum. Nutr. Diet. 2017, 31, 121-130. [CrossRef]

28. Dickson-Spillmann, M.; Siegrist, M. Consumers' knowledge of healthy diets and its correlation with dietary behaviour. J. Hum. Nutr. Diet. 2010, 24, 54-60. [CrossRef]

29. Worsley, A. Nutrition knowledge and food consumption: Can nutrition knowledge change food behaviour? Asia Pac. J. Clin. Nutr. 2002, 11, S579-S585. [CrossRef]

30. Barbosa, L.B.; Vasconcelos, S.M.L.; Correia, L.O.D.S.; Ferreira, R.C. Nutrition knowledge assessment studies in adults: A systematic review. Ciên. Saúde Colet. 2016, 21, 449-462. [CrossRef]

31. Ajzen, I. The theory of planned behavior. Organ. Behav. Hum. Decis. Process. 1991, 50, 179-211. [CrossRef]

32. Bandura, A. Social Foundations of Thought and Aaction: A Social Cognitive Theory; Prentice-Hall: Englewood Cliffs, NJ, USA, 1986.

33. Vidgen, H.A.; Gallegos, D. Defining food literacy and its components. Appetite 2014, 76, 50-59. [CrossRef]

34. Wallace, R.; Lo, J.; Devine, A. Tailored nutrition education in the elderly can lead to sustained dietary behaviour change. J. Nutr. Health Aging 2016, 20, 8-15. [CrossRef]

35. Kothe, E.J.; Mullan, B. A randomised controlled trial of a theory of planned behaviour to increase fruit and vegetable consumption. Fresh Facts. Appetite 2014, 78, 68-75. [CrossRef] [PubMed]

36. Dunstan, D.; Zimmet, P.Z.; A Welborn, T.; Cameron, A.J.; Shaw, J.; De Courten, M.; Jolley, D.; Mccarty, D.J. The Australian Diabetes, Obesity and Lifestyle Study (AusDiab)—methods and response rates. Diabetes Res. Clin. Pr. 2002, 57, 119-129. [CrossRef] 
37. AusDiab. The Australian Diabetes, Obesity and Lifestyle Study: Health Knowledge, Attitudes \& Practices Questionnaire. Available online: https://baker.edu.au/-/media/documents/impact/ausdiab/questionnaires/ ausdiab-health-knowledge-questionnaire-1999.pdf?la=en (accessed on 6 June 2019).

38. Hodge, A.M.; Patterson, A.J.; Brown, W.J.; Ireland, P.; Giles, G. The Anti Cancer Council of Victoria FFQ: Relative validity of nutrient intakes compared with weighed food records in young to middle-aged women in a study of iron supplementation. Aust. N. Z. J. Public Health 2000, 24, 576-583. [CrossRef] [PubMed]

39. Ireland, P.; Jolley, D.; Giles, G.; O’Dea, K.; Powles, J.; Rutishauser, I.; Wahlqvist, M.L.; Williams, J. Development of the Melbourne FFQ: A food frequency questionnaire for use in an Australian prospective study involving an ethnically diverse cohort. Asia Pac. J. Clin. Nutr. 1994, 3, 19-31.

40. National Health and Medical Research Council. National Health and Medical Research Council. Australian Dietary Guidelines (Reference N55a); National Health and Medical Research Council: Canberra, Australia, 2013.

41. Coyne, T.; Ibiebele, T.I.; McNaughton, S.A.; Rutishauser, I.H.E.; O’Dea, K.; Hodge, A.M.; McClintock, C.; Findlay, M.G.; Lee, A. Evaluation of brief dietary questions to estimate vegetable and fruit consumption-Using serum carotenoids and red-cell folate. Public Health Nutr. 2005, 8, 298-308. [CrossRef]

42. Talwar, D.; Ha, T.K.; Cooney, J.; Brownlee, C.; Jo'Reilly, D.S. A routine method for the simultaneous measurement of retinol, $\alpha$-tocopherol and five carotenoids in human plasma by reverse phase HPLC. Clin. Chim. Acta 1998, 270, 85-100. [CrossRef]

43. Dalton, M.; Cameron, A.J.; Zimmet, P.Z.; Shaw, J.E.; Jolley, D.; Dunstan, D.W.; Welborn, T.A. On behalf of the AusDiab Steering Committee Waist circumference, waist-hip ratio and body mass index and their correlation with cardiovascular disease risk factors in Australian adults. J. Intern. Med. 2003, 254, 555-563. [CrossRef]

44. Australian Institute of Health and Welfare. The Active Australia Survey: A Guide and Manual for Implementation, Analysis and Reporting. Available online: Aihw.gov.au/reports/physical-activity/activeaustralia-survey/contents/table-of-contents (accessed on 18 January 2020).

45. World Health Organization. Obesity: Preventing and Managing the Global Epidemic; WHO Technical Report Series 894; WHO: Geneva, Switzerland, 2000; pp. 1-253.

46. Trewin, D. Information Paper-Census of Population and Housing: Socio-Economic Indexes for Areas Australia 2001; Australian Bureau of Statistics: Canberra, Australia, 2003.

47. Colón-Ramos, U.; Rutten, L.J.F.; Moser, R.P.; Colón-López, V.; Martínez, A.P.O.; Yaroch, A.L. The Association Between Fruit and Vegetable Intake, Knowledge of the Recommendations, and Health Information Seeking Within Adults in the U.S. Mainland and in Puerto Rico. J. Health Commun. 2014, 20, 105-111. [CrossRef]

48. Erinosho, T.O.; Moser, R.P.; Oh, A.; Nebeling, L.C.; Yaroch, A.L. Awareness of the Fruits and Veggies-More Matters campaign, knowledge of the fruit and vegetable recommendation, and fruit and vegetable intake of adults in the 2007 Food Attitudes and Behaviors (FAB) Survey. Appetite 2012, 59, 155-160. [CrossRef]

49. Farragher, T.; Wang, W.C.; Worsley, A. The associations of vegetable consumption with food mavenism, personal values, food knowledge and demographic factors. Appetite 2016, 97, 29-36. [CrossRef]

50. Taylor, M.K.; Sullivan, D.K.; Ellerbeck, E.F.; Gajewski, B.J.; Gibbs, H.D. Nutrition literacy predicts adherence to healthy/unhealthy diet patterns in adults with a nutrition-related chronic condition. Public Health Nutr. 2019, 22, 2157-2169. [CrossRef] [PubMed]

51. Thompson, O.M.; Yaroch, A.L.; Moser, R.P.; Rutten, L.J.F.; Petrelli, J.M.; Smith-Warner, S.A.; Mâsse, L.C.; Nebeling, L. Knowledge of and Adherence to Fruit and Vegetable Recommendations and Intakes: Results of the 2003 Health Information National Trends Survey. J. Health Commun. 2011, 16, 328-340. [CrossRef] [PubMed]

52. Wardle, J.F.C.; Parmenter, K.; Waller, J. Nutrition knowledge and food intake. Appetite 2000, 34, $269-275$. [CrossRef] [PubMed]

53. Brewer, D.; Dickens, E.; Humphrey, A.; Stephenson, T. Increased fruit and vegetable intake among older adults participating in Kentucky's congregate meal site program. Educ. Gerontol. 2016, 42, 771-784. [CrossRef]

54. Cannoosamy, K.; Pem, D.; Bhagwant, S.; Jeewon, R. Is a Nutrition Education Intervention Associated with a Higher Intake of Fruit and Vegetables and Improved Nutritional Knowledge among Housewives in Mauritius? Nutrients 2016, 8, 723. [CrossRef] 
55. Clark, R.L.; Famodu, O.A.; Holásková, I.; Infante, A.M.; Murray, P.J.; Olfert, I.M.; McFadden, J.W.; Downes, M.T.; Chantler, P.D.; Duespohl, M.W.; et al. Educational intervention improves fruit and vegetable intake in young adults with metabolic syndrome components. Nutr. Res. 2019, 62, 89-100. [CrossRef]

56. Hersey, J.C.; Cates, S.C.; Blitstein, J.L.; Kosa, K.M.; Rivera, O.J.S.; Contreras, D.A.; Long, V.A.; Singh, A.; Berman, D.A. Eat Smart, Live Strong Intervention Increases Fruit and Vegetable Consumption Among Low-Income Older Adults. J. Nutr. Gerontol. Geriatr. 2015, 34, 66-80. [CrossRef]

57. Neville, C.E.; McKinley, M.C.; Draffin, C.R.; Gallagher, N.; Appleton, K.M.; Young, I.; Edgar, J.M.; Woodside, J.V. Participating in a fruit and vegetable intervention trial improves longer term fruit and vegetable consumption and barriers to fruit and vegetable consumption: A follow-up of the ADIT study. Int. J. Behav. Nutr. Phys. Act. 2015, 12, 158. [CrossRef]

58. Wagner, M.G.; Rhee, Y.; Honrath, K.; Salafia, E.H.B.; Terbizan, D. Nutrition education effective in increasing fruit and vegetable consumption among overweight and obese adults. Appetite 2016, 100, 94-101. [CrossRef]

59. Lara, J.; Hobbs, N.; Moynihan, P.; Meyer, T.D.; Adamson, A.J.; Errington, L.; Rochester, L.; Sniehotta, F.F.; White, M.; Mathers, J.C. Effectiveness of dietary interventions among adults of retirement age: A systematic review and meta-analysis of randomized controlled trials. BMC Med. 2014, 12, 60. [CrossRef]

60. Parekh, N.; Jiang, J.; Buchan, M.; Meyers, M.; Gibbs, H.; Krebs, P. Nutrition Literacy among Cancer Survivors: Feasibility Results from the Healthy Eating and Living Against Breast Cancer (HEAL-BCa) Study: A Pilot Randomized Controlled Trial. J. Cancer Educ. 2017, 33, 1239-1249. [CrossRef] [PubMed]

61. Pem, D.; Bhagwant, S.; Jeewon, R. A Pre and Post Survey to Determine Effectiveness of a Dietitian-Based Nutrition Education Strategy on Fruit and Vegetable Intake and Energy Intake among Adults. Nutrients 2016, 8, 127. [CrossRef] [PubMed]

62. Pollard, C.M.; Miller, M.; Woodman, R.J.; Meng, X.; Binns, C. Changes in Knowledge, Beliefs, and Behaviors Related to Fruit and Vegetable Consumption among Western Australian Adults from 1995 to 2004. Am. J. Public Health 2009, 99, 355-361. [CrossRef] [PubMed]

63. Livingstone, K.M.; Burton, M.; Brown, A.K.; A McNaughton, S. Exploring barriers to meeting recommendations for fruit and vegetable intake among adults in regional areas: A mixed-methods analysis of variations across socio-demographics. Appetite 2020, 153, 104750. [CrossRef] [PubMed]

64. Glasson, C.; Chapman, K.; James, E. Fruit and vegetables should be targeted separately in health promotion programmes: Differences in consumption levels, barriers, knowledge and stages of readiness for change. Public Health Nutr. 2010, 14, 694-701. [CrossRef]

65. Rekhy, R.; McConchie, R. Promoting consumption of fruit and vegetables for better health. Have campaigns delivered on the goals? Appetite 2014, 79, 113-123. [CrossRef]

66. Carter, O.B.; Pollard, C.M.; Atkins, J.F.; Milliner, J.M.; Pratt, I.S. 'We're not told why-we're just told': Qualitative reflections about the Western Australian Go for 2\&5®fruit and vegetable campaign. Public Health Nutr. 2010, 14, 982-988. [CrossRef]

67. Baker, A.H.; Wardle, J.F.C. Sex differences in fruit and vegetable intake in older adults. Appetite 2003, 40, 269-275. [CrossRef]

68. Hendrie, G.; Coveney, J.D.; Cox, D. Exploring nutrition knowledge and the demographic variation in knowledge levels in an Australian community sample. Public Health Nutr. 2008, 11, 1365-1371. [CrossRef]

69. Worsley, A.; Wang, W.C.; Byrne, S.; Yeatman, H. Different patterns of Australian adults' knowledge of foods and nutrients related to metabolic disease risk. J. Nutr. Sci. 2014, 3, e14. [CrossRef]

70. Vasconcelos, C.; Almeida, A.; Sá, C.; Viana, J.L.; Cabral, M.; Ramos, E.; Mendes, R. Nutrition-related knowledge and its determinants in middle-aged and older patients with type 2 diabetes. Prim. Care Diabetes 2020, 14, 119-125. [CrossRef] [PubMed]

71. De Vriendt, T.; Matthys, C.; Verbeke, W.; Pynaert, I.; De Henauw, S. Determinants of nutrition knowledge in young and middle-aged Belgian women and the association with their dietary behaviour. Appetite 2009, 52, 788-792. [CrossRef]

72. Fiuza-Luces, C.; Santos-Lozano, A.; Joyner, M.; Carrera-Bastos, P.; Picazo, O.; Zugaza, J.L.; Izquierdo, M.; Ruilope, L.M.; Lucia, A. Exercise benefits in cardiovascular disease: Beyond attenuation of traditional risk factors. Nat. Rev. Cardiol. 2018, 15, 731-743. [CrossRef] [PubMed] 
73. Khoramdad, M.; Vahedian-Azimi, A.; Karimi, L.; Rahimi-Bashar, F.; Amini, H.; Sahebkar, A. Association between passive smoking and cardiovascular disease: A systematic review and meta-analysis. IUBMB Life 2020, 72, 677-686. [CrossRef] [PubMed]

74. Ball, K.; Lamb, K.E.; Costa, C.; Cutumisu, N.; Ellaway, A.; Kamphuis, C.B.M.; Mentz, G.; Pearce, J.; Santana, P.; Santos, R.; et al. Neighbourhood socioeconomic disadvantage and fruit and vegetable consumption: A seven countries comparison. Int. J. Behav. Nutr. Phys. Act. 2015, 12, 1-13. [CrossRef] [PubMed]

75. Livingstone, K.M.; Olstad, D.L.; Leech, R.M.; Ball, K.; Meertens, B.; Potter, J.; Cleanthous, X.; Reynolds, R.; McNaughton, S.A. Socioeconomic Inequities in Diet Quality and Nutrient Intakes among Australian Adults: Findings from a Nationally Representative Cross-Sectional Study. Nutrients 2017, 9, 1092. [CrossRef]

Publisher's Note: MDPI stays neutral with regard to jurisdictional claims in published maps and institutional affiliations.

(C) 2020 by the authors. Licensee MDPI, Basel, Switzerland. This article is an open access article distributed under the terms and conditions of the Creative Commons Attribution (CC BY) license (http://creativecommons.org/licenses/by/4.0/). 